\title{
Papers
}

\section{ISIS-2: 10 year survival among patients with suspected acute myocardial infarction in randomised comparison of intravenous streptokinase, oral aspirin, both, or neither}

Colin Baigent, Rory Collins, Paul Appleby, Sarah Parish, Peter Sleight, Richard Peto on behalf of the ISIS-2 (Second International Study of Infarct Survival) Collaborative Group*

\begin{abstract}
Objective: To assess effects of intravenous streptokinase, one month of oral aspirin, or both, on long term survival after suspected acute myocardial infarction.

Design: Randomised, “2 2 2 factorial," placebo controlled trial.

Setting: 417 hospitals in 16 countries.

Subjects: 17187 patients with suspected acute myocardial infarction randomised between March 1985 and December 1987. Follow up of vital status complete to at least 1 January 1990 for $95 \%$ of all patients and to mid-1997 for the 6213 patients in United Kingdom.

Interventions: Intravenous streptokinase (1.5 MU in 1 hour) and oral aspirin (162 mg daily for 1 month) versus matching placebos.

Main outcome measures: Mortality from all causes during up to 10 years' follow up, with subgroup analyses based on 4 year follow up.

Results: After randomisation, 1841 deaths were recorded in days $0-35,991$ from day 36 to end of year 1,1478 in years 2-4, and 1230 in years 5-10. Allocation to streptokinase was associated with 29 (95\% confidence interval 20 to 38) fewer deaths per 1000 patients during days 0-35. This early benefit persisted (death rate ratio 0.98 (0.92 to 1.04) for additional deaths between day 36 and end of year 10), so that there were 28 (14 to 42 ) and 23 (2 to 44 ) fewer deaths per 1000 patients treated with streptokinase after 4 years and 10 years respectively. There was no evidence that absolute survival benefit increased with prolonged follow up among any category of patient, including those presenting early after symptoms started or with anterior ST elevation. Nor did the early benefits seem to be lost in any category (including those aged over 70). Allocation to one month of aspirin was associated with 26 (16 to 35 ) fewer deaths per 1000 during first 35 days, with little further benefit or loss during subsequent years (death rate ratio 0.99 (0.93 to 1.06) between day 36 and end of year 10). The early benefit obtained with combination of streptokinase and one month of aspirin also seemed to persist long term.
\end{abstract}

Conclusions: The early survival advantages produced by fibrinolytic therapy and one month of aspirin started in acute myocardial infarction seem to be maintained for at least 10 years.

\section{Introduction}

The second international study of infarct survival (ISIS-2) in 17187 patients with suspected acute myocardial infarction, ${ }^{1}$ together with the other large randomised trials, ${ }^{2-9}$ showed unequivocally that, in suitable patients, fibrinolytic therapy reduces early mortality. The Fibrinolytic Therapy Trialists' collaborative overview of their results indicates that treatment of 1000 patients who present with ST elevation or bundle branch block up to at least 12 hours from the onset of symptoms typically prevents about 20-30 deaths during the first month (30 per 1000 patients treated within 0-6 hours and 20 per 1000 treated within 7-12 hours of onset of symptoms). ${ }^{10}$ ISIS-2 also showed that the benefits of early treatment with aspirin were largely independent of, and additive to, those of fibrinolytic therapy. For every 1000 patients treated with one month of medium dose aspirin (such as $162 \mathrm{mg}$ daily), about 25 deaths and 10-15 non-fatal reinfarctions or strokes were avoided during the first month. ${ }^{1}$

Follow up of some of the larger trials of fibrinolytic therapy has shown reliably that a substantial survival benefit is maintained for at least the first 6-12 months. ${ }^{11-13}$ Longer term follow up, however, has been reported only on much smaller numbers: just over 1000 randomised patients in the APSAC intervention mortality study (AIMS) ${ }^{14}$ and smaller numbers in a few other studies. ${ }^{15-17}$ These have suggested that the early survival benefits persist with prolonged follow up ${ }^{18}$ or may even increase in certain types of patient (such as those treated early after onset of symptoms ${ }^{19}{ }^{20}$ and those with anterior infarction ${ }^{15}{ }^{16}$ ), but there were relatively few deaths after the first year of follow up in those trials. Hence, the chief aim of this report of extended follow up in the large ISIS-2 trial is to provide more reliable estimates of the long term effects of fibrinolytic therapy, as well as of a short course of aspirin, both overall and among particular categories of patient.

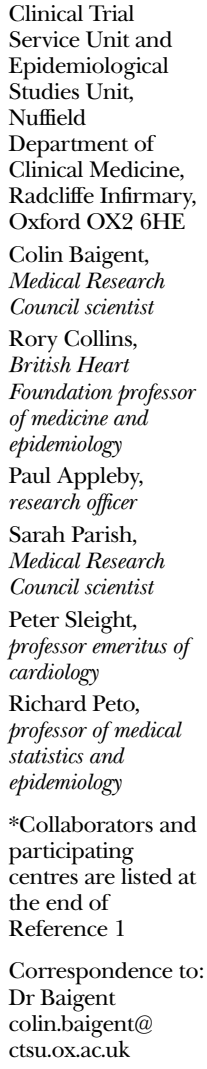

BMJ 1998;316:1337-43 


\section{Patients and methods}

\section{Eligibility and randomisation}

The design of ISIS-2 has previously been described in detail. ${ }^{1}$ Patients were eligible if they were within 24 hours of the onset of symptoms of suspected myocardial infarction, with no clear indications for, or contraindications to, streptokinase or aspirin. Electrocardiographic changes at entry were not a requirement (although a pre-randomisation electrocardiogram was required for central reading), and no age restriction was imposed by the protocol. Entry to the study was by telephone to central, 24 hour, randomisation services.

\section{Treatment}

A " $2 \times 2$ factorial" study design was used. Half of all patients were allocated randomly to receive $1.5 \mathrm{MU}$ streptokinase and half to receive matching placebo, infused intravenously over about 1 hour. Half of all patients were also allocated randomly to receive oral aspirin (exact dose $162.5 \mathrm{mg}$ in enteric coated tablets) and half to receive matching placebo, given daily for 1 month from a calendar pack. In all other respects physicians were free to use whatever additional treatment they considered necessary. Compliance with allocated treatment was high, ${ }^{1}$ but, irrespective of whether the study treatment was actually given, patients remained in their originally allocated treatment group for an intention to treat analysis (see below).

\section{Recruitment and follow up}

Between 5 March 1985 and 31 December 1987, a total of 17187 patients were randomised by 417 hospitals in 16 countries (see acknowledgements in original report ${ }^{1}$ ). This large size ensured good balance between the treatment groups for the main pre-randomisation features that were measured (aided by a "minimisation" balancing algorithm ${ }^{21}$ ) and should do likewise for those that were not

The previous report was of events occurring in hospital and of vascular mortality within 35 days (estimated then to be $98 \%$ complete) and up to a median of 15 months. ${ }^{1}$ Follow up after discharge was only of mortality, through government records (Office for National Statistics in the United Kingdom) where possible, but otherwise directly with patients or their relatives. The aim of the present study was to extend follow up of vital status to at least 1 January 1990 (that is, two years after the last patient entered the study), with the information available after that date being mostly for the patients in the United Kingdom and censored at 30 June 1997 to allow time for central notification of deaths. This resulted in a median of 38 months of follow up among survivors randomised outside the United Kingdom and 130 months among the survivors of the 6213 patients in the United Kingdom. Among all survivors, $95.1 \%$ have been followed to 1 January 1990: follow up to 35 days is now $98.8 \%$ complete, with $96.0 \%$ followed to 2 years and $57.7 \%$ to 4 years. Among the survivors in the United Kingdom, $97.6 \%$ have been followed to 6 years, $97.3 \%$ to 8 years, and $83.1 \%$ to 10 years. There were no systematic differences in follow up between the treatment groups.

For the original report, cause of death information was sought from death certification and subdivided by the trial coordinator, blind to treatment allocation, into "definitely non-vascular" causes and "vascular" causes (that is, definitely or possibly vascular, or unknown). In the first month only $0.4 \%$ of the deaths were classified as definitely non-vascular, and overall in the first report only about $2 \%$ of the available deaths could be classified as definitely non-vascular (with similar numbers in each treatment group) - and, even among those few deaths, some may have been partly or wholly due to vascular causes. Hence, the present report is of deaths from any cause.

Principal comparisons and statistical methods

The two principal comparisons were of mortality among all those allocated the one hour infusion of streptokinase versus that among all those allocated placebo infusion, and of mortality among all those allocated one month of aspirin tablets versus that among all those allocated placebo tablets. These comparisons were analysed in three main ways, all of which take appropriate and unbiased account of the duration of follow up for each patient.

First, time to death analyses used log rank methods, ${ }^{22}$ with calculations of exact variance and censoring at the date of last follow up for each patient (up to 10 years), and are illustrated by Kaplan-Meier survival curves.

Second, death rate ratios and their confidence intervals were calculated from log rank "observed minus expected" numbers of deaths, ${ }^{22}$ and their variances, for days $0-35$ (the early period) and for day 36 to the end of year 10 based on patients at risk at the start of each of six time periods which involved similar numbers of deaths-day 36 to end of year 1; annually thereafter to end of year 4 (that is, years 2,3 , and 4 separately); years 5 and 6 combined; and years 7 to 10 combined.

Third, the absolute differences in life table estimates of survival were calculated at 35 days and after 4 years of follow up (at which time the proportion of patients with follow up was still substantial enough to provide stable estimates in certain subgroups). Two sided $\mathrm{P}$ values are cited, and $2 \mathrm{P}>0.1$ is generally considered not significant. We used $95 \%$ confidence intervals for overall analyses and 99\% confidence intervals for subgroup analyses to make some allowance for the effects of multiple comparisons.

\section{Results}

Intravenous streptokinase (8592 patients) $v$ placebo infusion (8595 patients)

Overall effects on 4 year and 10 year survival During the first 35 days of follow up, allocation to streptokinase was associated with a highly significant death rate ratio of $0.75(95 \%$ confidence interval 0.69 to 0.83 ; $2 \mathrm{P}<0.0001$ ) (fig 1 ). This corresponds to prevention of about a quarter of the early deaths, and to an absolute improvement of 29 (20 to 38) fewer deaths per 1000 patients treated (table). Between day 36 and the end of the first year, allocation to streptokinase was associated with a smaller, and not conventionally significant, additional reduction in death (death rate ratio 0.89 (99\% confidence interval 0.75 to 1.05 ); $2 \mathrm{P}=0.06$ ) (fig 1 ). During each of the three subsequent years of follow up, 
allocation to streptokinase was not associated with any significant difference in death rate. After 4 years of follow up there were still 28 (95\% confidence interval 14 to 42$)$ fewer deaths per 1000 patients who had been treated with streptokinase (table).

During year 5, follow up was available both for those patients who had been randomised during the first 9 months of recruitment in any participating country and for all survivors in the United Kingdom. Follow up in subsequent years was exclusively among these British survivors, with substantial numbers of deaths recorded in this smaller cohort during this period (fig 1). There was still no significant difference in subsequent death rates between the treatment groups, either in years 5-6 (death rate ratio $0.94 \quad(99 \%$ confidence interval 0.76 to 1.17$)$ ) or in years $7-10$ (death rate ratio 1.02 (0.84 to 1.24$)$ ) (fig 1 ). Overall, between day 36 and the end of year 10, streptokinase was not associated with any additional difference in mortality (death rate ratio $0.98(95 \%$ confidence interval 0.92 to 1.04$) ; 2 \mathrm{P}>0.1)$. Hence, after the large divergence in survival during days $0-35$, a slight divergence during the rest of the first year was balanced by a slight convergence in subsequent years (fig 2).

Effects on 4 year survival in particular categories of patient Substantial numbers of the patients have been followed for at least 4 years, which allows a reasonably reliable assessment of the effects of fibrinolytic therapy on 4 year survival among particular subgroups (table).

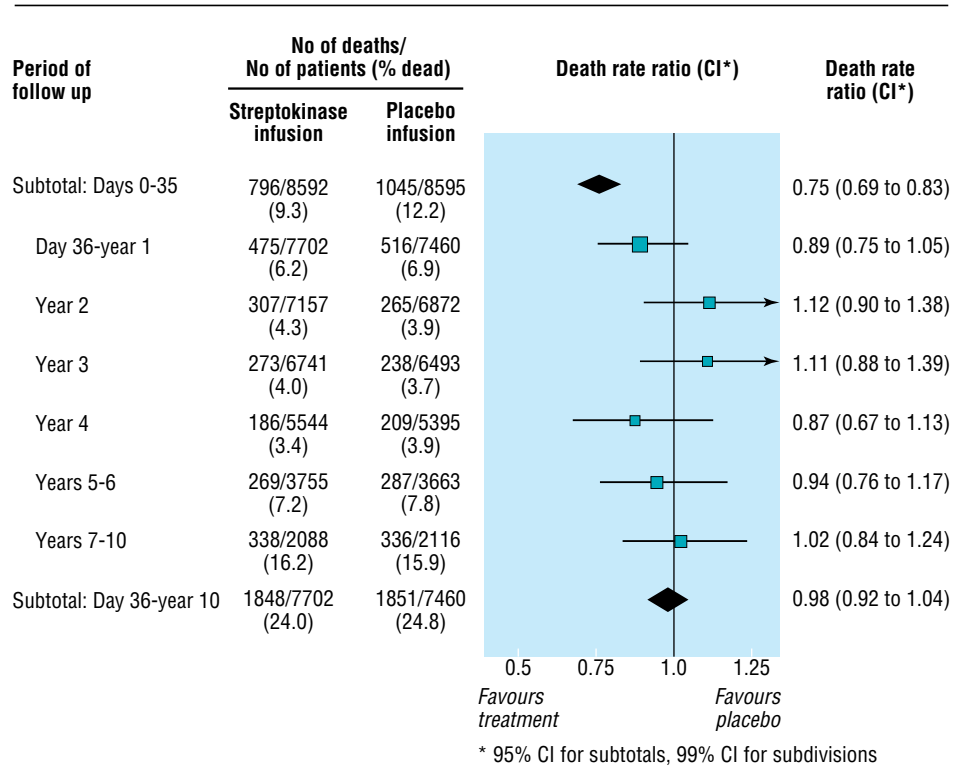

Fig 1 Proportional effects of streptokinase infusion on deaths among patients with suspected acute myocardial infarction during days $0-35$ and day 36 to 10 years. In each period the death rate ratio among all patients allocated streptokinase compared with that among all those allocated placebo is calculated from the log rank of observed minus expected number of deaths, and its variance. Death rate ratios and $95 \%$ confidence intervals during subtotals of days $0-35$ and day 36 to 10 years are represented by diamonds, while death rate ratios and $99 \%$ confidence intervals during subdivisions of the latter period are represented by black squares (area proportional to amount of "statistical information") and bars. Only for days $0-35$ is difference between streptokinase and placebo separately significant $(\mathrm{P}<0.00001$; all others $2 P>0.05)$

Estimated survival percentages and absolute benefits of streptokinase both overall and in patient subgroups during days 0-35 and day 0 to year 4

\begin{tabular}{|c|c|c|c|c|c|c|c|c|}
\hline \multirow[b]{3}{*}{ Category of patient at entry to study } & \multirow{2}{*}{\multicolumn{2}{|c|}{$\begin{array}{l}\text { No of patients } \\
\text { randomised }\end{array}$}} & \multicolumn{3}{|c|}{ Follow up in days $0-35$} & \multicolumn{3}{|c|}{ Follow up in day 0 to year 4} \\
\hline & & & \multicolumn{2}{|c|}{ Survival (\%) } & \multirow{2}{*}{$\begin{array}{c}\text { Absolute benefit }\left(\mathrm{Cl}^{\star}\right) \\
\text { per } 1000 \text { patients }\end{array}$} & \multicolumn{2}{|c|}{ Survival (\%) } & \multirow{2}{*}{$\begin{array}{c}\text { Absolute benefit }\left(\mathrm{Cl}^{*}\right) \\
\text { per } 1000 \text { patients }\end{array}$} \\
\hline & SK & Placebo & SK & Placebo & & SK & Placebo & \\
\hline \multicolumn{9}{|l|}{ Hours from onset: } \\
\hline $0-3$ & 2551 & 2557 & 91.8 & 87.5 & 43 (21 to 65$)$ & 77.7 & 73.0 & 48 (15 to 80$)$ \\
\hline $4-6$ & 2799 & 2803 & 90.4 & 87.8 & 26 (4 to 47 ) & 73.8 & 72.2 & 16 (-16 to 48$)$ \\
\hline $7-12$ & 2018 & 2008 & 89.4 & 87.4 & 19 (-7 to 45$)$ & 72.8 & 70.4 & $24(-15$ to 62$)$ \\
\hline $13-24$ & 1224 & 1227 & 91.3 & 89.0 & $23(-8$ to 54$)$ & 74.2 & 72.2 & 20 (-29 to 69$)$ \\
\hline \multicolumn{9}{|l|}{ Age (years): } \\
\hline$<70$ & 6949 & 6910 & 93.0 & 90.2 & 27 (15 to 40$)$ & 79.9 & 77.5 & 23 (4 to 42 ) \\
\hline$\geqslant 70$ & 1643 & 1685 & 81.0 & 77.7 & $33(-3$ to 69$)$ & 53.1 & 49.0 & $41(-7$ to 89$)$ \\
\hline \multicolumn{9}{|l|}{ Sex: } \\
\hline Male & 6522 & 6612 & 92.0 & 88.9 & 31 (18 to 44$)$ & 76.3 & 73.2 & 31 (10 to 51$)$ \\
\hline Female & 2023 & 1930 & 86.6 & 84.2 & 24 (-5 to 53$)$ & 70.3 & 68.2 & $21(-18$ to 60$)$ \\
\hline \multicolumn{9}{|l|}{ Pre-randomisation ECG: } \\
\hline Bundle branch block & 373 & 385 & 79.3 & 74.8 & $45(-33$ to 124$)$ & 55.0 & 52.3 & 27 (-70 to 124$)$ \\
\hline Anterior ST elevationt & 2067 & 2056 & 89.1 & 81.8 & 73 (44 to 101$)$ & 72.0 & 65.8 & 62 (24 to 101$)$ \\
\hline Inferior ST elevation & 2128 & 2152 & 92.5 & 90.9 & 15 (-6 to 37$)$ & 78.2 & 76.1 & $21(-13$ to 56$)$ \\
\hline ST depression & 610 & 605 & 81.3 & 82.4 & $-11(-68$ to 46$)$ & 61.6 & 60.8 & 9 (-66 to 83$)$ \\
\hline Otherł & 2398 & 2288 & 95.4 & 93.8 & 16 (-1 to 33$)$ & 81.7 & 79.4 & $22(-9$ to 54$)$ \\
\hline \multicolumn{9}{|l|}{ Diabetes: } \\
\hline Yes & 620 & 669 & 87.9 & 82.5 & 54 (3 to 105 ) & 62.0 & 59.3 & 27 (-49 to 102$)$ \\
\hline No & 7880 & 7832 & 91.0 & 88.3 & 26 (14 to 39$)$ & 75.9 & 73.2 & 27 (9 to 46 ) \\
\hline \multicolumn{9}{|l|}{ Previous myocardial infarction: } \\
\hline Yes & 1497 & 1442 & 87.0 & 82.7 & 43 (9 to 77 ) & 59.7 & 57.8 & $18(-30$ to 67$)$ \\
\hline No & 7003 & 7059 & 91.6 & 88.9 & 26 (13 to 39 ) & 78.2 & 75.1 & 32 (12 to 51$)$ \\
\hline \multicolumn{9}{|l|}{ Treatment comparisons: } \\
\hline SK plus aspirin $v$ aspirin alone & 4292 & 4295 & 91.9 & 89.2 & 27 (11 to 44 ) & 75.7 & 73.3 & $24(-1$ to 49$)$ \\
\hline SK alone $v$ double placebo & 4300 & 4300 & 89.5 & 86.4 & 31 (13 to 49) & 73.9 & 70.7 & 32 (6 to 58 ) \\
\hline Overall & 8592 & 8595 & 90.7 & 87.8 & 29 (20 to 38$)$ & 74.8 & 72.0 & 28 (14 to 42 ) \\
\hline
\end{tabular}

SK=streptokinase, ECG=electrocardiogram. ${ }^{*} 95 \%$ confidence intervals given for overall absolute benefits at day 35 and end of year 4 , and $99 \%$ confidence intervals for absolute benefits in subgroups of patients. †Includes 164 streptokinase patients and 152 placebo patients who also had inferior ST elevation. łIncludes some patients with normal electrocardiograms. 


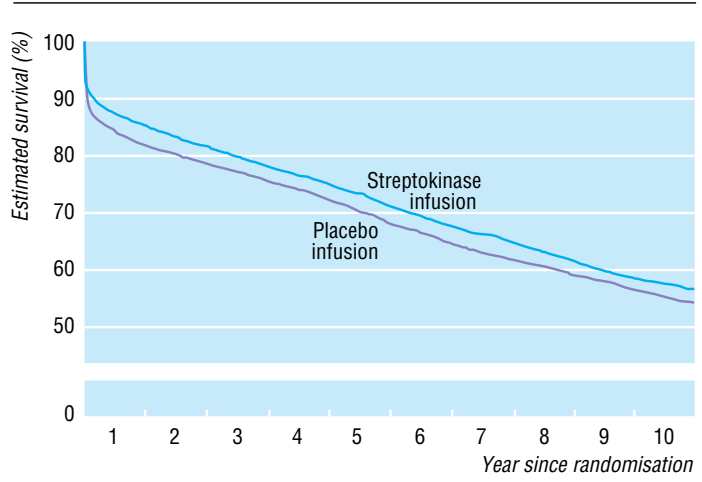

Fig 2 Life table estimate of 10 year survival with streptokinase. Comparisons of all patients allocated intravenous streptokinase $v$ all those allocated placebo. (Numbers of deaths during each period, and numbers of patients at risk at start of the period, are given for each treatment arm in fig 1)

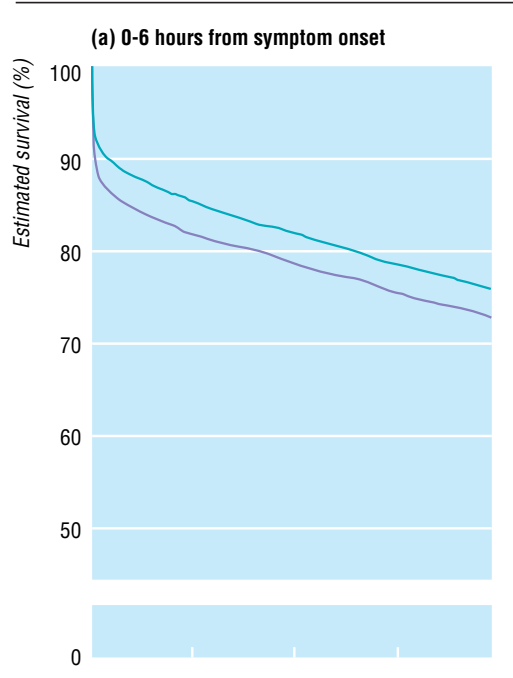

(b) Anterior ST elevation
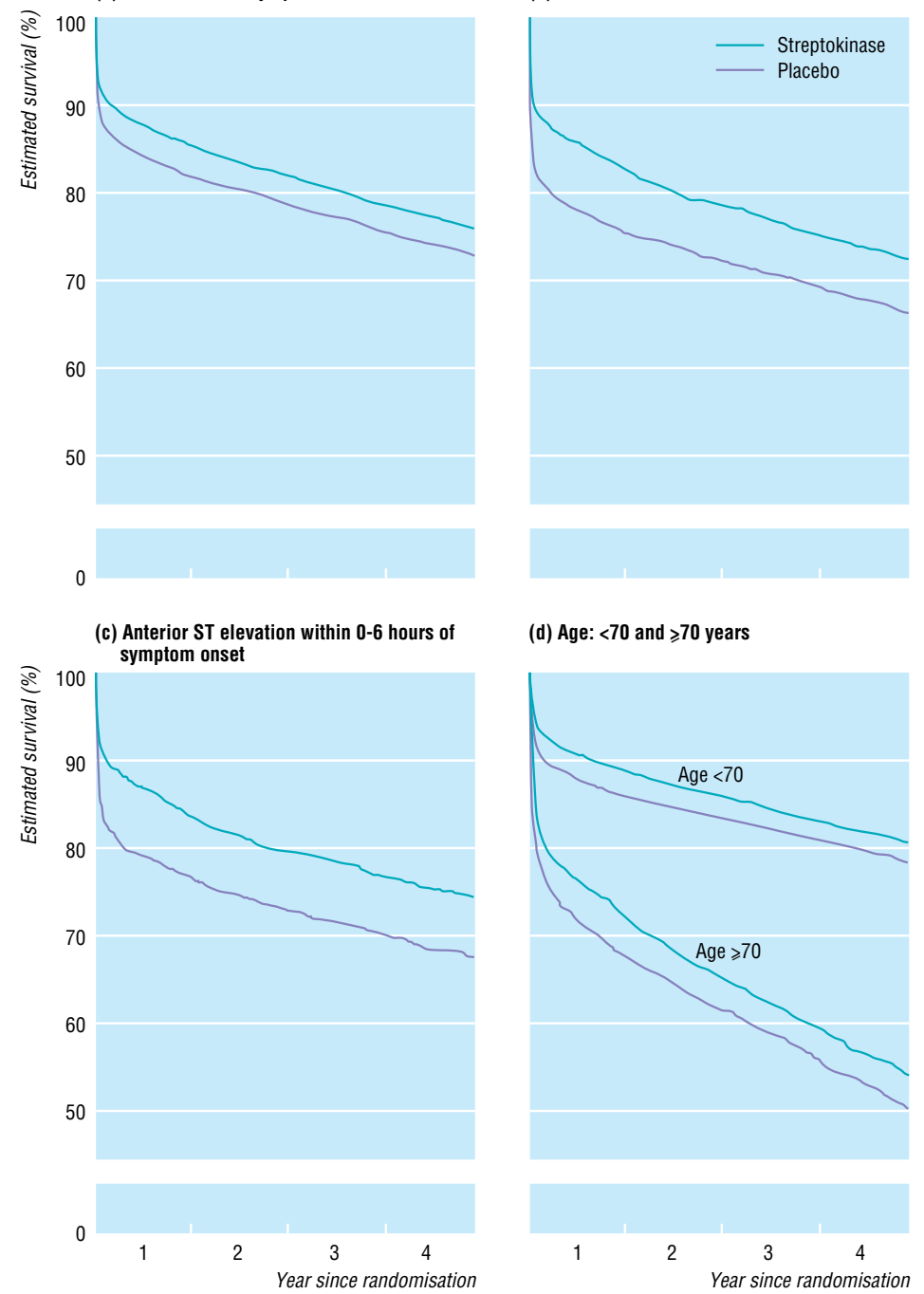

Fig 3 Life table estimates of 4 year survival in various patient categories. Comparisons of patients allocated streptokinase $v$ those allocated placebo restricted to those patients presenting (a) within 0-6 hours of onset of symptoms, (b) with anterior ST elevation, (c) with anterior ST elevation within $0-6$ hours of symptoms starting, and (d) aged $<70$ and $\geqslant 70$ years
Among patients randomised within $0-6$ hours of the onset of symptoms, the absolute benefit of 31 (99\% confidence interval 9 to 54) fewer deaths per 1000 at the end of year 4 was about the same as it had been at day 35 (34 (19 to 50) fewer per 1000) (fig 3a). Thus, the additional deaths after day 35 were not much affected by whether or not streptokinase had been given (death rate ratio 0.99 (0.86 to 1.13) between day 36 and the end of year 4; $2 \mathrm{P}>0.1)$. The same was true when attention was further restricted just to those who had been randomised 0-3 hours after symptoms started (death rate ratio $0.93(0.76$ to 1.13 ) between day 36 and the end of year $4 ; 2 \mathrm{P}>0.1)$. Similarly, there was no evidence of any later survival gains among patients presenting with anterior ST elevation (death rate ratio 0.99 ( 0.80 to 1.21$)$ between day 36 and the end of year 4; $2 \mathrm{P}>0.1$ ) (fig $3 \mathrm{~b}$ ). Consequently, the absolute benefit at the end of year 4 for patients with anterior ST elevation was still about the same as it had been at day 35 (table), even when such patients presenting within 6 hours of symptoms starting were considered separately (fig 3 c).

Although about half of the patients aged 70 or over at entry died within 4 years of randomisation, the early benefit persisted. Indeed, the absolute reduction in 4 year mortality with streptokinase seemed to be at least as great among those aged 70 or over $(41$ ( -7 to 89$)$ fewer deaths per 1000) as among those aged less than 70 (23 (4 to 42) fewer deaths per 1000) (table, fig 3d).

Oral aspirin (8587 patients) $v$ placebo tablets $(8600$ patients)

During the first 35 days of follow up, allocation to one month of oral aspirin was associated with a highly significant death rate ratio of $0.78(95 \%$ confidence interval 0.71 to $0.85 ; 2 \mathrm{P}<0.0001$ ) (fig 4 ). This corresponds to prevention of about a quarter of the early deaths and to an absolute improvement of 26 (16 to 35) fewer deaths per 1000 patients treated. Between day 36 and the end of year 1, and for each of the five subsequent periods that were considered, the use of aspirin during the first month (that is, before day 36) was not associated with any significant additional difference in the death rate (fig 4). Hence, all of the survival benefit of an early, one month course of oral aspirin seemed to accrue during the first month, with little further benefit or loss during subsequent years (death rate ratio 0.99 (0.93 to 1.06) between day 36 and the end of year 10 ; $2 \mathrm{P}>0.1$ ) (figs 4 and 5).

\section{Combination of streptokinase and aspirin}

The original report of ISIS-2 showed that the early benefits of streptokinase and of aspirin were approximately additive, ${ }^{1}$ and the same now seems to be true of the long term benefits. At the end of year 4, the absolute benefits of streptokinase were still similar among patients who had been allocated to aspirin (24 (99\% confidence interval -1 to 49 ) fewer deaths per 1000 patients allocated streptokinase plus aspirin compared with aspirin alone) and among patients who had not been allocated aspirin (32 (6 to 58) fewer deaths per 1000 allocated streptokinase alone rather than double placebo) (table). Overall, between day 36 and the end of year 10, allocation to the combination of streptokinase plus aspirin was not associated with any additional benefit (death rate ratio 0.97 (95\% confidence interval 0.89 to 1.06 ); $2 \mathrm{P}>0.1$ ) compared with 
allocation to neither. Hence, the early survival benefit obtained with the combination (55 (42 to 68) fewer deaths per 1000 at day 35) persisted largely unaltered in the longer term (42 (13 to 71) fewer deaths per 1000 at 10 years) (fig 6$)$.

\section{Discussion}

Long term effects of intravenous fibrinolytic therapy Large randomised trials had previously shown that the survival benefits of fibrinolytic therapy persist for at least a year after treatment. ${ }^{11-13}$ But information about the longer term persistence of these benefits was limited to studies that recorded relatively few later deaths. By contrast, this report involves about 1500 deaths between the start of the second year and the end of the fourth year after fibrinolytic therapy and a further 1200 deaths in the subsequent period up to 10 years. Hence, it provides reliable evidence about the persistence of the early survival advantages.

The annual mortality in ISIS-2 during each year of follow up after the first was about $4 \%$, both among patients initially allocated streptokinase and among those allocated placebo. Consequently, after the clear separation of the survival curves in the first month and a slight further separation during the rest of the first year, there was only slight convergence during subsequent years such that the absolute benefit at one month persisted largely unchanged for at least 10 years (fig 2). This finding should not be materially affected by the different durations of observation available for different patients, since follow up in this placebo controlled study was unbiased with respect to the allocated treatment, and the methods of survival analysis used take account, in an unbiased fashion, of the date of last follow up for each patient (see methods section).

It had been suggested that the absolute survival benefit of fibrinolytic therapy might increase for some years, at least among patients treated within the first few hours after the onset of symptoms ${ }^{19}{ }^{20}$ and those presenting with anterior infarction or other evidence of a large volume of myocardium at risk. ${ }^{15}{ }^{16}$ Among the large numbers of patients studied in these and other subgroups of ISIS-2, however, there was no evidence that the absolute benefits increased (or decreased) with prolonged follow up. Ejection fraction and patency of the coronary artery related to the infarct are independently associated with long term survival. ${ }^{23}{ }^{24}$ But, although fibrinolytic therapy can produce quite large improvements in ejection fraction and patency of the coronary artery during the first few days, the differences observed after a month or so between patients allocated fibrinolytic therapy and controls are relatively small. ${ }^{25}$ Moreover, the relation between later mortality and pre-discharge ejection fractions in the range $40-60 \%$ is relatively shallow, ${ }^{27}$ so that differences of a few percentage points ${ }^{25}$ within this range-which is likely to encompass most of the patients studied in ISIS-2 and other trials of fibrinolytic therapy-should probably not be expected to translate into much further difference in later mortality. This conclusion is supported by the present results, but that does not rule out the possibility that the absolute benefits of fibrinolytic therapy might increase with prolonged follow up in some particular group of patients at very high risk.

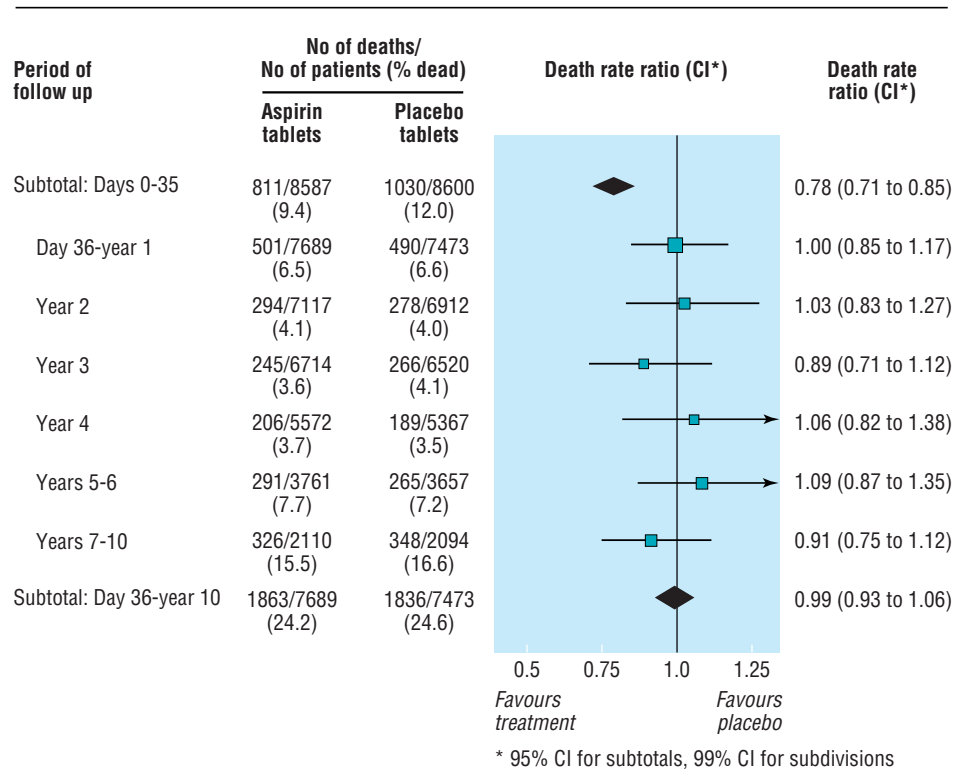

Fig 4 Proportional effects of aspirin on death during days 0-35 and day 36 to 10 years. Death rate ratios compare those allocated one month of oral aspirin with those allocated placebo. (Conventions as for fig 1)

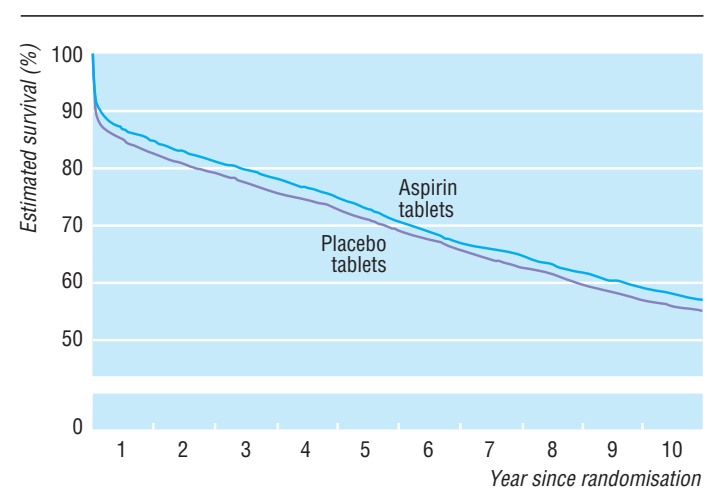

Fig 5 Life table estimate of 10 year survival with aspirin.

Comparisons of all patients allocated one month of oral aspirin $v$ all those allocated placebo. (Numbers of deaths during each period, and numbers of patients at risk at start of the period, are given for each treatment arm in fig 4 . Follow up beyond year 5 is among patients in United Kingdom only)

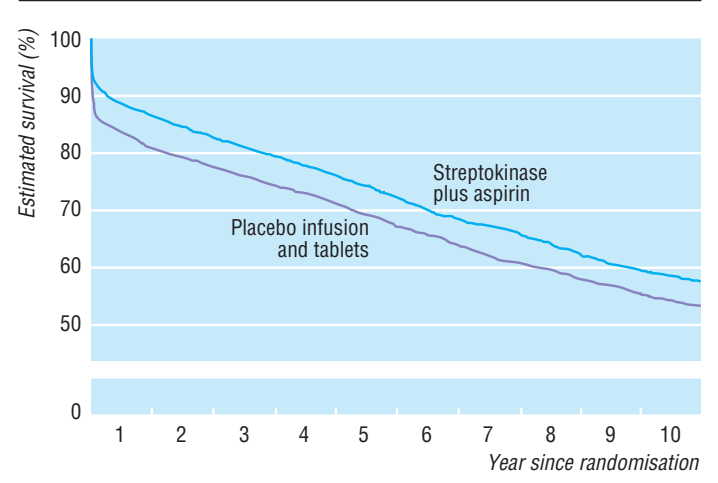

Fig 6 Life table estimate of 10 year survival with streptokinase plus aspirin. Comparisons of all patients allocated intravenous streptokinase plus oral aspirin $v$ all those allocated double placebo. (Follow up beyond year 5 is among patients in United Kingdom only) 
For elderly patients presenting with suspected acute myocardial infarction, one reservation expressed about the use of fibrinolytic therapy is that any short term survival advantage might be only transitory because of their high underlying mortality. ${ }^{28}$ In a survey of about 4000 consecutive patients with acute myocardial infarction treated between January 1993 and June 1994 in 11 European countries, fibrinolytic therapy was received by about two thirds of those considered, on review, to be suitable for it, and age was one of the main reasons for undertreatment. ${ }^{29}$ Among such patients, those aged over 65 were only about half as likely as younger patients to receive fibrinolytic therapy. Similar findings have also been reported for the United States. ${ }^{30}$ There are some encouraging signs that the use of fibrinolytic therapy in elderly patients may be increasing, ${ }^{31}$ but there still seems to be substantial room for improvement-particularly since ISIS-2 now indicates that the absolute survival advantage after several years is at least as great among older as among younger patients.

\section{Long term effects of oral aspirin}

ISIS-2 is the only large randomised trial to have assessed the effects on mortality of a short course of medium dose (162 mg daily) oral aspirin started immediately during suspected acute myocardial infarction. One month of aspirin treatment was associated with a highly significant absolute improvement in survival at 35 days which still persisted after several years, and the long term benefits of short term aspirin treatment and of fibrinolytic therapy were approximately additive. ISIS-2 did not assess the additional effects of continuing aspirin treatment after the first month (which would, in such a blinded study, have occurred to a similar extent among those who had been allocated aspirin or placebo tablets for the first month). The long term benefits of prolonged antiplatelet treatment started later after myocardial infarction have, however, been shown by the Antiplatelet Trialists' collaborative overview of 11 randomised trials, chiefly involving aspirin, in which 36 (SD 6) serious vascular events (that is, myocardial infarction, stroke, or vascular death) were avoided per 1000 survivors of myocardial infarction treated for about two years, with the likelihood of additional benefits from even longer treatment. ${ }^{32}$

\section{Conclusion}

Long term follow up of the large number of patients in ISIS-2 provides clear evidence that the early survival advantage produced by fibrinolytic therapy in acute myocardial infarction persists for many years after treatment. The early survival advantage with the short term aspirin regimen studied also persisted long term, and this prolonged benefit was additive to that of fibrinolytic therapy. Moreover, studies of prolonged antiplatelet treatment after myocardial infarction indicate that these benefits can be increased further by continuing aspirin treatment for some years after myocardial infarction.

The chief acknowledgement is to the 17187 patients who agreed to participate.

Contributors: The most important contributors are the thousands of doctors and nurses in the 417 participating hospitals who collaborated with the national coordinators in each country (see original report ${ }^{1}$ for list of participating centres and
- Large randomised trials have shown that the survival benefits of intravenous fibrinolytic therapy for patients with acute myocardial infarction persist for at least one year, but there is relatively little information about longer term effects

- By contrast, this report from the ISIS-2 trial of intravenous streptokinase and of one month of oral aspirin includes nearly 4000 deaths between the start of year 2 and the end of year 10

- The early survival benefits of fibrinolytic therapy persist for at least 10 years after treatment and do not seem to increase or decrease with prolonged follow up in any category of patients, including elderly subjects

- The survival benefits of short term aspirin treatment in acute myocardial infarction also persist long term and are additional to those of fibrinolytic therapy, and other studies show that these benefits can be increased by continuing aspirin treatment for some years after myocardial infarction

investigators). The study and its long term follow up were coordinated by the Steering Committee of ISIS-2: D Hunt, J Varigos (Australia); F Dienstl, P Lechleitner (Austria); G De Backer, M Kornitzer (Belgium); J Cairns, A G Turpie (Canada); F Pedersen, E Sandoe, J Kyst Madsen (Denmark); R Kala, J Heikkilä (Finland); J-P Boissel, A Leizorovicz (France); R Schröder (Germany); J Horgan, D O'Callaghan (Ireland); G Tognoni, M G Franzosi (Italy, GISSI liaison); H White (New Zealand); J Kjekshus, A Reikvam, J Kahrs (Norway); V Valentin (Spain); L Wilhelmsen, L Lundkvist (Sweden); R Malacrida, M Genoni, T Moccetti (Switzerland); R Collins, P Sleight, R Peto, S Parish, C Baigent, P Dove, S Cederholm Williams (United Kingdom); C Hennekens, S Yusuf (United States). Gale Mead and Cathy Harwood typed the manuscript, and Heather Halls, Deborah Jackson, and Rosemarie Schroder assisted with long term follow up. The listed authors, who are guarantors of the paper, analysed the present results and wrote this manuscript in collaboration with the steering committee on behalf of the ISIS-2 Collaborative Group.

Funding: The original study was supported by Behringwerke, a subsidiary of Hoechst, the makers of the streptokinase used, with aspirin and its placebo donated by Sterling Drugs. The study was, however, designed, conducted, analysed and interpreted independently of the companies, and the present long term follow up was made possible by support from the British Heart Foundation and UK Medical Research Council. Conflict of interest: None.

1 ISIS-2 (Second International Study of Infarct Survival) Collaborative Group. Randomised trial of intravenous streptokinase, oral aspirin, both, or neither among 17,187 cases of suspected acute myocardial infarction: ISIS-2. Lancet 1988;ii:349-60.

2 ISAM (Intravenous Streptokinase in Acute Myocardial Infarction) Study Group. A prospective trial of intravenous streptokinase in acute myocardial infarction (ISAM): mortality, morbidity and infarct size at 21 days. NEngl J Med 1986;314:1465-71.

3 Gruppo Italiano per lo Studio della Streptochinasi nell'Infarto miocardico (GISSI). Effectiveness of intravenous thrombolytic treatment in acute myocardial infarction. Lancet 1986;i:397-402.

4 The AIMS (APSAC Intervention Mortality Study) Trial Study Group. Effects of intravenous APSAC on mortality after acute myocardial infarction. Preliminary report of a placebo-controlled clinical trial. Lancet 1988;i:545-9.

5 Wilcox RG, von der Lippe G, Olsson CJ, Jensen G, Skene AM, Hampton JR for the ASSET (Anglo-Scandinavian Study of Early Thrombolysis) Study Group. Trial of tissue plasminogen activator for mortality reduction in acute myocardial infarction (ASSET). Lancet 1988;ii:525-30.

6 Rossi P, Bolognese L on behalf of Urochinasi per via Sistemica nell'Infarto Miocardico (USIM) Collaborative Group. Comparison of intravenous urokinase plus heparin versus heparin alone in acute myocardial infarction. Am J Cardiol 1991;68:585-92. 
7 ISIS-3 (Third International Study of Infarct Survival) Collaborative Group. ISIS-3: A randomised trial of streptokinase vs tissue plasminogen activator vs anistreplase and of aspirin plus heparin vs aspirin alone among 41,299 cases of suspected acute myocardial infarction. Lancet 1992;339:753-70.

8 EMERAS (Estudio Multicéntrico Estreptoquinasa Repúblicas de América del Sur) Collaborative Group. Randomised trial of late thrombolysis in patients with suspected acute myocardial infarction. Lancet 1993;342:767-72.

9 LATE Study Group. Late assessment of thrombolytic efficacy (LATE) study with alteplase 6-24 hours after onset of acute myocardial infarction. Lancet 1993;342:759-66.

10 Fibrinolytic Therapy Trialists' Collaborative Group. Indications for fibrinolytic therapy in suspected acute myocardial infarction: collaborative overview of early mortality and major morbidity results from all randomised trials of more than 1000 patients. Lancet 1994;343:311-22.

11 Gruppo Italiano per lo Studio della Streptochinasi nell'Infarto miocardico (GISSI). Long-term effects of intravenous thrombolysis: final report of the GISSI study. Lancet 1987;ii:871-4.

12 Schröder R, Neuhaus K-L, Leizorovicz A, Linderer T, Tebbe U for the ISAM Study Group. A prospective placebo-controlled double-blind multicenter trial of intravenous streptokinase in acute myocardial infarction (ISAM) long-term mortality and morbidity. J Am Coll Cardiol 1987;9:197-203.

13 Wilcox RG, von der Lippe G, Olsson CG, Jensen G, Skene AM, Hampton JR for the Anglo-Scandinavian Study of Early Thrombolysis. Effects of alteplase in acute myocardial infarction: 6-month results from the ASSET study. Lancet 1990;335:1175-8.

14 Hillis WS, Chamberlain DA, de Bono DP, Fox KAA, Murray RG, Julian DG, et al for the AIMS Study Group. Intravenous anistreplase in acute myocardial infarction: continued reduction in mortality up to 5 years: long-term results of the AIMS study [abstract]. Eur Heart J 1992; 13(suppl):305

15 Simoons ML, Vos J, Tijssen JGP, Vermeer F, Verheugt FWA, Krauss XH, et al. Long-term benefit of early thrombolytic therapy in patients with acute myocardial infarction: 5-year follow-up of a trial conducted by the Interuniversity Cardiology Institute of the Netherlands. J Am Coll Cardiol 1989;14:1609-15.

16 Cerqueira MD, Maynard C, Ritchie JL, Davis KB, Kennedy JW. Long-term survival in 618 patients from the Western Washington streptokinase in myocardial infarction trials. J Am Coll Cardiol 1992;20:1452-9.

17 Lenderink T, Simoons ML, Van Es G-A, Van de Werf F, Verstraete M, Arnold AER for the European Cooperative Study Group. Benefit of thrombolytic therapy is sustained throughout five years and is related to TIMI perfusion grade 3 but not grade 2 flow at discharge. Circulation $1995 ; 92: 1110-6$

18 Van de Werf F. Thrombolysis for acute myocardial infarction: why is there no extra benefit after hospital discharge? Circulation 1995;91:2862-4.

19 White HD. Thrombolytic therapy for patients with myocardial infarction presenting after 6 hours. Lancet 1992;340:221-2.
20 Rawles J. Magnitude of benefit from earlier thrombolytic treatment in acute myocardial infarction: new evidence from Grampian region early anistreplase trial (GREAT). BMJ 1996;312:212-6.

21 White SJ, Freedman LS. Allocation of patients to treatment groups in a controlled clinical study. Br J Cancer 1978;37:849-57.

22 Peto R, Pike MC, Armitage P, Breslow NE, Cox DR, Howard SV, et al. Design and analysis of randomised clinical trials requiring prolonged observation of each patient. Part II: Analysis and examples. Br J Cancer 1977;35:1-39.

23 White HD, Cross DB, Eiliot JM, Norris RM, Yee TW. Long-term prognostic importance of patency of the infarct-related coronary artery after thrombolytic therapy for acute myocardial infarction. Circulation 1994;89:61-7.

24 Lamas GA, Flaker GC, Mitchell G, Smith SC, Gersh BJ, Wun C-C, et al for the Survival and Ventricular Enlargement Investigators. Effect of infarct artery patency on prognosis after acute myocardial infarction. Circulation 1995;92:1101-9.

25 Granger CB, White HD, Bates ER, Ohman EM, Califf RM. A pooled analysis of coronary artery patency and left ventricular function after intravenous thrombolysis for acute myocardial infarction. Am J Cardiol 1994;74:1220-8

26 Harrison JK, Califf RM, Woodlief LH, Kereiakes D, George BS, Stack RS, et al for the TAMI Study Group. Systolic left ventricular function after reperfusion therapy for acute myocardial infarction. An analysis of determinants of improvement. Circulation 1993;87:1531-41.

27 Volpi A, De Vita C, Franzosi MG, Geraci E, Maggioni AP, Mauri F, et al for the Ad Hoc Working Group of the Gruppo Italiano per lo Studio della Soprovvivenza nell'Infarto miocardico (GISSI)-2 data base. Determinants of 6-month mortality in survivors of myocardial infarction after

28 Gurwitz JH, Goldberg RJ, Gore JM. Coronary thrombolysis for the elderly? JAMA 1991;265:1720-3.

29 European Secondary Prevention Study Group. Translation of clinical trials into practice: a European population-based study of the use of thrombolysis for acute myocardial infarction. Lancet 1996;347:1203-7.

30 Rogers WJ, Bowlby LJ, Chandra NC, French WJ, Gore JM, Lambrew CT, et al for the Participants in the National Registry of Myocardial Infar the Partip of to 1993). Observations from the National Registry of Myocardial Infarction. Circulation 1994;90:2103-14.

31 Gurwitz JH, Gore JM, Goldberg RJ, Rubison M, Chandra N, Rogers WJ for the Participants in the National Registry of Myocardial Infarction. Recent age-related trends in the use of thrombolytic therapy in patients who have had acute myocardial infarction. Ann Intern Med 1996;124:283-91.

32 Antiplatelet Trialists' Collaboration. Collaborative overview of randomised trials of antiplatelet therapy. I: Prevention of death, myocardial infarction, and stroke by prolonged antiplatelet therapy in various categories of patients. BMJ 1994;308:81-106.

(Accepted 2 February 1998)

\title{
Fetal and maternal contributions to risk of pre-eclampsia: population based study
}

\author{
Rolv Terje Lie, Svein Rasmussen, Helge Brunborg, Håkon K Gjessing, Erik Lie-Nielsen, \\ Lorentz M Irgens
}

\begin{abstract}
Objective: To use familial patterns of recurrence of pre-eclampsia to investigate whether paternal genes expressed in the fetus contribute to the mother's risk of pre-eclampsia and whether mother's susceptibility to pre-eclampsia is related to maternal inheritance by mitochondrial DNA.

Design: Linked data on pregnancies of different women who had children with the same father, and subsequently linked data on pregnancies of half sisters who either had same mother and different fathers or had same father and different mothers.

Setting: Population based data from the Medical Birth Registry of Norway covering all births since 1967

(about 1.7 million) and the Norwegian Central

Population Register.

Main outcome measures: Relative risk of pre-eclampsia after a previous pre-eclamptic pregnancy in the family. Relative risks approximated by odds ratios.
\end{abstract}

Results: If a woman becomes pregnant by a man who has already fathered a pre-eclamptic pregnancy in a different woman her risk of developing pre-eclampsia is 1.8 (95\% confidence interval 1.2 to 2.6$)$. If the woman has a half sister who had pre-eclampsia and with whom she shares the same mother but different fathers the risk of pre-eclampsia is 1.6 (0.9 to2.6). If the two sisters have the same father but different mothers the risk is 1.8 (1.01 to 2.9).

Conclusions: Both the mother and the fetus contribute to the risk of pre-eclampsia, the contribution of the fetus being affected by paternal genes. Mitochondrial genes, which are transmitted by mothers, do not seem to contribute to the risk.

\section{Introduction}

Pre-eclampsia is a life threatening complication of pregnancy characterised by high blood pressure and proteinuria $^{1}$; it occurs in about $3 \%$ of all pregnancies. ${ }^{2}$ 